\title{
Management in National Parks - A Policy for Tanzania
}

Professor E. Walter Russell CMG was invited by the Ford Foundation, at the instance of the Director and Trustees of the Tanzania National Parks, to visit the five parks and make basic policy recommendations for their management. The following extracts from his report, ${ }^{*}$ in which he defines the main aim of national parks, looks at the management possibilities and shows the vital importance of research, are of interest not only to Tanzania but also to all concerned about the future of national parks throughout the world, particularly in the low-income countries of Africa, Asia and elsewhere, where the problems may be quite different from those in wealthier countries.

- A NATIONAL park is an area set aside where man can enjoy, as a A privileged visitor, the plants and animals that are indigenous to that environment under conditions as little affected by his presence as possible, and the Trustees of a Park hold it in trust for the benefit of future generations as well as for the present.

'While I believe this statement can be accepted as the goal of management, it may be difficult to interpret in practice. First it is often uncertain what plants and animals are indigenous to the area because human activity in the recent past has created the present environment, although the range of uncertainty is rapidly being narrowed by the work of ecologists. Second, the environment may be constantly changing, due in part to natural recovery when gross human interference is reduced, partly to the very marked changes in climate that occur over periods of years, and partly to other reasons which are direct consequences of the major objective. Third, since man has been a firemaker for many thousands of years, an environment which is the consequence of the regular burning of the dead vegetation in most dry seasons must often be considered indigenous.

'A national park is, however, in a very real sense a man-made environment, and must be recognised as such. It has a definite boundary within which hunting and poaching are suppressed as completely as possible, thus creating a sanctuary where the animals tend to be confined, even though, in conditions where man's influence is small, their range of movement would have extended far beyond its boundaries, particularly in years of drought or other unfavourable conditions. Further, since the park is a sanctuary, animals not normally found there may adapt themselves to it in order to escape interference by man.

'It is well worth while at this stage to look at other possible goals for national park policies. One possible goal is to freeze the environment, in the exact form it had at the moment the national park was formed. It

*The full text of Professor Russell's report A Management Policy for the Tanzania National Parks can be obtained in a booklet from the FPS office in London, price $5 s$ (6d postage). Professor Russell, formerly Director of the East African Agriculture and Forestry Research Organisation, 1955-64, is now Professor of Soil Science at Reading University. 
would be exceedingly difficult to formulate a management plan to achieve this goal, for the environment is constantly changing, nor is there usually any over-riding scientific or human interest in the park conditions at that moment. A second possible goal is to allow nature to take its course from the moment the park is formed, and not interfere in any way with any changes that might take place. But, because the creation of a national park introduces a number of artificial factors into the environment, there is no rational reason for adopting this policy except that it involves no positive management practices by the park's staff; it is in fact the management goal of a strict nature reserve. The adoption of this policy may lead to radical changes in the habitats within the park and such changes normally involve a loss or destruction by some animal species of certain habitats that are valuable or essential to the welfare of other species.

'A third policy is to remove or neutralise as far as possible every influence man might have on the environment. This would involve, for example, shooting every animal that was driven into the park by man's activity outside it, as well as preventing any fires entering or being started in the park by man.

'A fourth possible policy, which I hope can be dismissed out of hand, is to manage the park as a zoo, so that the tourist can see the maximum number of species of animals, without regard to the naturalness of the conditions in which the animals are living.

'A fifth possibility is to manage the parks as ranches, to produce a surplus of animals that can be regularly cropped and sold as meat. I believe this policy is entirely inconsistent with the goal of a national park as a place where man can enjoy watching animals living in as near their natural habitat as possible, and it would also be inconsistent with one that encouraged tourists from overseas to visit and enjoy the parks.

'Finally the parks could be run primarily as ecological or ethological research laboratories. While I shall be arguing later on for the necessity of a scientific research service as a part of the Management Division of the national parks I could not possibly recommend that the parks should be run for the benefit of research scientists. The necessary research work must be carried out in a way consistent with the primary rôle of the parks already proposed.

'There is, however, a very real possibility that the goal as expressed in my first paragraph may not always be fully acceptable for the Tanzania national parks. It is probably, even almost certain, that some of the habitats in a national park at the time of its creation are the direct result of human interference, but nevertheless consititute habitats that one wants to preserve. The obvious examples are fire-induced grasslands and wooded grassland, which carry large numbers of many plains-game species under conditions that allow visitors to see them. Since this is a man-induced habitat, its preservation is not included in the basic goal of a national park, as given above, but its loss cannot be accepted without discussion. It is such a characteristic game habitat in the Tanzania national parks that I believe its disappearance would constitute a very important and serious loss which should not be lightly accepted. I would suggest that these 
habitats be accepted as amongst those little affected by man's presence, for the effect of his presence is indirect, and there is every reason to believe that dry season fires have been characteristic of these habitats for very long periods of time, conceivably since man first became a maker of fires.'

\section{Strict Nature Reserves}

Professor Russell considers the desirability of creating strict nature reserves in the IUCN sense, that is, reserves where conservation of some particular habitat or animal requires the exclusion of human beings as completely as possible. He suggests that such reserves might be within a national park, and in some cases the tourist could be allowed to enjoy them, for example the crater floor of Ngurdoto, where it is possible to see from the crater rim animals enjoying themselves under conditions of effectively no human interference at all. An example of a strict nature reserve which the general public should not be allowed access to, but could enjoy at second-hand through cinema or television, is probably that part of the new Gombe Stream National Park containing the chimpanzee.

On the question of the parks' rôle as sanctuaries, he believes that if animals such as elephant are driven into a national park from outside they should be allowed to stay, unless there is some important reason to the contrary, such as destruction of the habitat required for other species.

Professor Russell considers the introduction of new species into a national park, and suggests that there is a strong case for introducing a species that has become extinct in the park as a result of human activitye.g. the lesser kudu in the Lake Manyara park - and also for introducing a species for which the habitat has become suitable as a result of the removal of man's farming activities. He also regards as admissible the introduction of individual animals of a species that is low in numbers in order to augment the numbers, for example black rhino where the existing population appears to be well below the carrying capacity of the habitat, provided this does not cause any appreciable change in the habitat; but dangerous animals such as lion, rhino or elephant, which have lost their fear of man through being reared by humans, should not be introduced. In the difficult case of animals in danger of extinction, care must be taken to ensure that sub-species, e.g. of white rhino do not interbreed. The creation of new reserves is a better solution.

\section{Aims of Management}

Professor Russell then discusses the aims of management policy that must be decided: whether management is to be for the benefit of all animal species in the park, or only the indigenous ones; whether it is to preserve a variety of habitats, which might lead to the necessity of reducing over-large animal populations; whether to speed up vegetation changes due, for example, to the cessation of farming; and the problems involved in ensuring that visitors have the minimum effect on the animals. Visitors also raise a difficult problem if, in times of severe drought, animals are to be seen obviously dying of starvation. Tanzania suffers less than Kenya in this respect, but dying lion cubs can present a problem. 'If the biologists 
can show that this is purely a transient problem and that it is not an important mechanism for the control of the size of the lion population, then I believe a good case can be made for giving the cubs these few meals. But if it is shown that cubs in this condition are a characteristic of a population that is rising too high, then I consider it is undesirable practice and the wardens should be given authority to kill or remove these cubs unobtrusively.

'Management of the environment in a national park should always be kept to the absolute minimum consistent with the basic goals of the parks, but there are circumstances when man must actively disturb the processes going on in the park, usually to maintain some habitats that are being destroyed by certain animals but are needed by others. For one must maintain the local species in their maximum variety and in reasonable abundance. The tools of management for altering the biological conditions in a park are few and crude. The two most obvious ones are the rifle, for reducing the population of any particular wild animal, and fire for controlling the vegetation.'

He describes the rifle as 'an absolute last resort tool' in a national park, and fire as a powerful tool, on the use of which policy must be decided.

\section{What to do About Fire}

'In most parks uncontrolled fires come through every dry season, and the management decision is either to let them come through, or to prevent any fire coming through, or to control the fire so that it comes through at a predetermined time or at a predetermined interval of years. These decisions are of great importance in acacia woodlands and parklands which form such a characteristic habitat in parts of most national parks, for these are fire-induced habitats carrying a very distinctive group of wild animals and birds, and which must therefore be maintained, but they can be quite sensitive to the burning régime that is practised. There are still very many difficult research problems to be solved before we can use this tool of the controlled burn to the best advantage in maintaining this group of habitats.'

On the question of research Professor Russell writes: 'The trustees of a national park can only perform their executive management duties efficiently and in accord with their basic policy if they are continuously supplied with information on the changes in the habitat and the animal numbers that are taking place; for neither of these will remain static for any length of time in any national park. Further, they need to be kept informed of the likely consequences if these changes continue, so they can consider what actions they may be required to take well in advance of the actual need. Finally they need advisers who can tell them what kind of action they could take, and its likely consequences. Only a research service can provide this information.

'This service has two functions. The first is what I will call a monitoring service, with responsibility for keeping a continuous check on the changes taking place in the vegetation and animal numbers in the various regions of the parks. It is essentially a service requiring plant and animal ecologists 
and so can be made to provide information on the effects of a number of types of change of management on the vegetation patterns, such as the effects of different régimes of burning or grazing. The second is more a biological research service, dealing with research on specific problems, usually on a short-term basis, related to the fauna or flora of a park, such as the food preferences, digestive physiology, reproductive behaviour, and diseases and parasites of the various species of animals. Provided the work is competently carried out, it will not normally need to be repeated unless new discoveries show that certain aspects of the problems had not been looked at. This service should provide the trustees with information on possible new methods for controlling change in the size of the animal populations.

'Eventually, every national park should have a proper ecological monitoring service attached to it, and the biologists constituting the service should be full-time members of the national parks service. Their work will not only be to keep a continuous check on all the ecological changes taking place in the parks but also to carry out essential management-oriented research on the major ecological problems of each park. This work is continuing work, and for that reason should be done by permanent members of the park's staff. It is therefore very desirable that these posts be filled by African, and preferably Tanzanian, biologists who have a real interest in these problems of field biology and wildlife management, and that they should be filled as fast as suitable graduates can be trained for them.

'It is very gratifying to see that the Director of the national parks has already taken active steps, in conjunction with his research staff, to set up such a monitoring service. Already accurate descriptions of the vegetation in many areas have been made, supplemented with photographs, often along traverse lines, and aerial photographs; and these records have been copied with complete sets kept in different places to ensure, as far as possible, that they are available in the future whenever needed. This work, which in the Serengeti is better developed and more advanced than anywhere else in Africa, needs to be strengthened and expanded as soon as possible. It will also lead to a fuller understanding of the present and past ecological conditions prevailing in the parks and their surrounding areas, and allow an assessment to be made of the efficiency of management in maintaining the variety of habitats and help to suggest ways of improving the methods in use.

'A very important research problem that this service could investigate as a matter of urgency is the exact conditions required for the regeneration or maintenance of the open acacia woodlands and grasslands that are such a characteristic feature of many areas in the national parks, and which contain characteristic assemblages of mammals and birds. This is a habitat that may be unstable in the sense that it is only a part of a natural vegetation cycle which goes from open grassland through young acacia thicket to mature trees in open parkland back to grassland as the trees die. The time scale of the cycle is probably strongly affected by the frequency of fire, and regeneration of some species of acacia will not take place under 
the trees, because they suppress the growth of seedlings. Seed of these species germinates only after passing through the digestive tract of a browsing animal, such as an elephant or gazelle, and the animal will have moved well away from the tree whose seed it ate before it deposits the seed on the ground in its dung. Since these trees form a very important item in the diet of the elephant, and considerable numbers are killed every year either by being barked or knocked down, they can probably only be maintained in parks containing elephants if the factors controlling their germination and growth are fully understood. This problem has already been recognised, and work on certain aspects has been in progress for several years, but it could justify much larger resources being devoted to its solution than have been available in the past.

\section{Short-term Prospects}

'The more biological research should also be largely management oriented, and it will usually be concerned with specific problems each of which should only require a strictly limited number of years. This type of work can be carried out at the Serengeti Research Institute, which, since it is dependent on outside funds for most of its finance, cannot recruit staff on a permanent basis. Most of this work will therefore have to be done by expatriate biologists recruited on short-term contracts until the financial position of the parks is much better assured. The Institute could also continue the policy of housing suitable visiting scientists who wish to work on problems of relevance to the parks or for which the parks supply the ecological habitats needed for the work. But the presence of research workers in a national park may be inconsistent with the goals of park management unless they and their equipment are inconspicuous, for one of these goals is to allow visitors to enjoy the wildlife in as near an undisturbed state and natural conditions as possible. This means that all research programmes must be approved by a suitable body and the present procedure whereby the Scientific Council of the Serengeti Research Institute is made responsible for approving research programmes is obviously the correct one.

'Two other types of research are also needed. The first is on developing improved methods for fire control, both to prevent fire getting into areas during the dry season, and for the efficient use of fire at different periods in the dry season. This kind of research into management methods is difficult and costly both to organise and to staff, but it is very important because the controlled use of fire is the most powerful tool of habitat management available to the trustees. The second, less urgent, need is for sociological research into the behaviour of visitors to the parks, to encourage them to co-operate with the trustees in their task of maintaining the parks as areas where the influence of man on wildlife is as small as possible, and to keep themselves as unobtrusive as possible. This will often involve the visitors, and their guides, willingly agreeing to requests that they should keep to certain tracks, or should keep away from certain areas, and should behave in a seemly way in the presence of the game animals.' 